\title{
TELEOLOGÍA JURÍDICA DE LA PATENTE DE INVENCIÓN, UNA MIRADA SISTEMÁTICA
}

\author{
David Francisco Franco Moreno \\ Maestría en Derecho Constitucional en (C), Universidad de la Sabana, Bogotá, (Colombia). Abogado, Universidad \\ Santo Tomás, Bucaramanga (Colombia). Profesional, Tribunal Administrativo de Tunja. (Colombia). \\ Correo electrónico:frafranquito@hotmail.com
}

\section{Resumen}

La definición de la patente de invención como institución jurídica debe efectuarse a la luz de su finalidad como un monopolio legal temporal de explotación que excluye del uso gratuito de la información por parte de terceros no autorizados. En otras palabras, la finalidad última de la patente es el estímulo a la difusión de la investigación científica y no su privatización excluyente, pues sólo de tal forma se armoniza la tensión entre el derecho humano a la protección del ingenio humano, y el derecho humano del acceso a la ciencia y la tecnología. Así las cosas, ni la patente protege información que no aporte novedad a la humanidad, ni la patente protege a inventores que ejerzan su uso exclusivo de forma abusiva o contra hominem. Tal situación es verificable no sólo en la legislación internacional de los derechos humanos, sino en la misma legislación comercial, tanto internacional como en la comunitaria de la Comunidad Andina de Naciones.

Palabras Clave:Patente de invención, acceso a la ciencia y la tecnología, free riders, teleología, axiología, requisitos de patentabilidad, licencia obligatoria.

\begin{abstract}
The patent definition must be made in order to it's purpose as a temporary legal monopoly of exploitation of the free and unauthorized information using. In other words, the ultimate purpose of the patent is the dissemination of scientific research encouraging. In that way could be harmonized the tension between the human rights to the protection of the private interest, and the access to science and technology. So, the patent don't protects no new information, neither abusive or against hominem use or them. This situation is verifiable in the international law of human rights, and in the commercial and Communitarian law.
\end{abstract}

Keywords: Patent, access to science and technology, free riders, teleology, axiology, patentability requirements, compulsory license.

\section{Résumé}

La définition du brevet de l'invention comme d'institution juridique doit être effectuée à la lumière de son but comme un monopole légal temporel de l'exploitation qu'il exclut de l'usage gratuit de l'information de la part de troisièmes non autorisés. Dans d'autres mots, le dernier but du brevet est la stimulation à la diffusion de la recherche scientifique et de non sa privatisation exclusive, puisque seulement de telle forme la tension est harmonisée entre les droits de l'homme à la protection du génie humain, et les droits de l'homme de l'accès à la science et la technologie. J'ai pris les choses, le brevet protège l'information qui n'apporte pas de nouveauté à l'humanité, le brevet protège les inventeurs qui exercent son usage exclusif de forme abusive ou contre hominem. Telle situation est vérifiable non seulement dans la législation internationale des droits de l'homme, mais dans la même législation commerciale, tant internationale comme dans la communautaire de la communauté andine de nations.

Mots-clés: le Brevet d'invention, de l'accès à la science et la technologie, free riders, une téléologie, axiología, des conditions requises de brevetabilité, de permission obligatoire. 

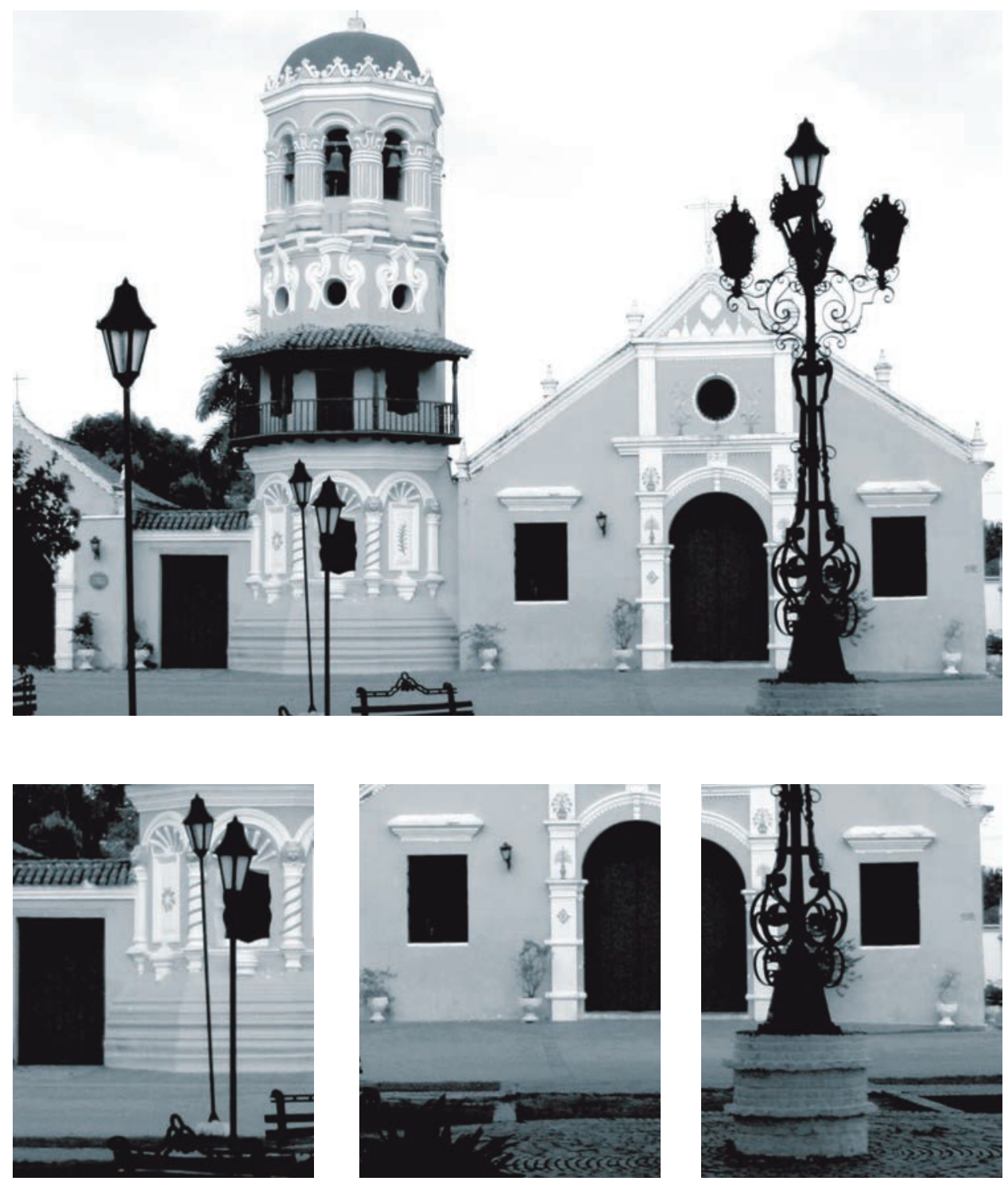

Iglesia de Santa Bárbara - Mompóx - Colombia Martín Emilio Hernández Manrique 


\section{TELEOLOGÍA JURÍDICA DE LA PATENTE DE INVENCIÓN, UNA MIRADA SISTEMÁTICA*}

David Francisco Franco Moreno

La patente de invención es una institución jurídica de especial relevancia en el mundo empresarial contemporáneo. Al ser una figura jurídica ligada a la innovación se relaciona directamente con el consumo de bienes y servicios, especialmente en la posibilidad para los consumidores de adquirir productos que no existirían de no ser por la capacidad innovadora del empresario.

El Código de Comercio, por ejemplo, sitúa a la patente como uno de los más importantes intangibles con que cuenta el empresario para desarrollar su actividad lucrativa. No es gratuito que el inciso segundo del artículo 516 del Código de Comercio, integre la propiedad industrial al establecimiento de comercio, de modo que se entienda la inescindibilidad existente entre empresa y propiedad industrial. De otro lado como institución ligada al consumidor, la patente de invención se sitúa como un engranaje del sistema productivo e innovador que permite la explotación del conocimiento en favor del mercado y sus participantes. ${ }^{1}$

La relevancia de la patente se extiende de forma principalísima a la comunidad internacional, pues en torno a ella se entretejen importantes relaciones y se construyen comunidades u organizaciones para desarrollar el comercio internacional. Por ejemplo, la propiedad industrial es uno de los ejes centrales en torno a los que nació la Comunidad Andina de Naciones (CAN), organizaciones como la OMPI o la OMC, y los tratados de libre comercio entre los países, como el reciente firmado TLC entre los Estados Unidos de América y la República de Colombia, que posee un acápite completo para la propiedad industrial.

* El texto se deriva del trabajo de investigación adelantado por el autor sobre propiedad intelectual desarrollado a partir de la investigación inicial sobre estado del arte sobre patentes en Colombia realizada para el levantamiento del estado del arte en el tema. Universidad Santo Tomás, Bucaramanga (Colombia).

1 Más adelante se estudiará cómo según el ordenamiento Comunitario Vigente de la CAN en Colombia, los requisitos de patentabilidad implican la innovación y la obligación de explotación suficiente en términos de mercado a cargo del titular de la patente, lo cual impide la exclusión injustificada del contenido informativo protegido por la patente. 
Para Colombia, en atención a su pertenencia a la CAN, la propiedad industrial es regulada por las Decisiones de la Comisión del Acuerdo de Cartagena, que no son simples directrices no vinculantes de la comunidad, sino que en razón del Protocolo modificatorio del tratado de creación del tribunal de justicia del Acuerdo de Cartagena, suscrito en la ciudad de Cochabamba, Bolivia, a los veintiocho (28) días del mes de mayo de 1996 y ratificado por Colombia mediante la ley 457 de 1998, ingresan directamente al ordenamiento jurídico Colombiano con fuerza de Ley de la República. (Ley 457, 1998).

Al efectuar la breve caracterización señalada, pueden encontrarse cuatro pilares fundantes del ordenamiento jurídico relativo a la propiedad industrial, estos son:

a. que es una normatividad dispersa en diversas clases de fuentes heterogéneas a lo largo y ancho del ordenamiento jurídico,

b. que el legislador de la Institución de la Patente de Invención es, en la mayoría de los casos, el legislador internacional, en escenarios variados,

c. Los acuerdos políticos entre Estados, de acuerdo a las conveniencias de los Países, fraguan el contenido de la protección de la propiedad industrialpatente, $\mathrm{y}$

d. en la legislación de la Patente de Invención, entran en juego diversidad de intereses como el del empresario, el del consumidor, y el de la humanidad en general, por desarrollarse en el marco de la innovación, y por lo tanto, del progreso de los pueblos.

Lo anterior plantea dos cuestionamientos por resolver

1) ¿Cuál es la teleología de la patente de invención? y

2) ¿De qué forma deben resolverse los posibles conflictos de intereses entre los actores participantes en la innovación y el consumo de bienes innovadores?

La vía encontrada para resolver dichos cuestionamientos es un estudio sistemático del ordenamiento jurídico, en atención a la dispersión de fuentes y multiplicidad de intereses que giran en torno a la figura jurídica.

Esta labor es importante en la medida que la multiplicidad de intereses que confluyen en la patente de invención, deberían ser un foco de desarrollo, en el entendido de su colaboración armónica, pero en lugar de ello, en ocasiones se torna en un núcleo de tensiones de intereses y/o derechos, más aún cuando la patente se acerca al campo de sectores especialmente sensibles como los medicamentos y la salud.

Sólo en la medida en que se comprenda sistemáticamente tal institución jurídica podrá dimensionarse su papel dentro del ordenamiento y la forma de resolver las posibles tensiones generadas ya sea entre empresarios entre sí o entre empresarios y consumidores. 


\section{La patente de invención y su objeto de protección}

La Constitución Política consagra la protección de la propiedad intelectual en términos generales en su artículo 61: "El Estado protegerá la propiedad intelectual por el tiempo y mediante las formalidades que establezca la ley." (Constitución Política de Colombia, 1991, Art. 61)

El Código Civil, pese a ser una normatividad tan antigua, también prevé una norma similar, en los siguientes términos: "Artículo 671. Las producciones del talento o del ingenio son una propiedad de sus autores. Esta especie de propiedad se regirá por leyes especiales." (Código Civil)

Como puede advertirse en ambas normas, se hace mención de una normatividad especial que definirá las formalidades, procedimientos y contenido del derecho a la protección de los productos del ingenio humano.

En la actualidad, dichas normas son las definidas por la CAN y la regla vigente es la decisión 486 de la Comisión del acuerdo de Cartagena, norma en la cual no existe una definición legal taxativa de la institución.

Sin tal definición legal, para lograr hacer una aproximación a la misma, se hace necesario acudir a otros elementos existentes en las normas, como lo son el objeto de protección, a los requisitos de patentabilidad, a las restricciones a la patentabilidad y, finalmente, a los derechos y deberes que ella confiere.

\section{El objeto de protección, la información}

Desde la perspectiva de objeto de la protección, la patente de invención es una forma sui géneris de propiedad, en razón a las características propias del objeto que protege.

La propiedad industrial no se circunscribe a la protección de objetos en sí mismos, sino a la guarda de invenciones o mejor aún, de ideas que puedan producir cuerpos ciertos o procedimientos que impliquen un avance en la ciencia y en la tecnología (Decisión 486 de la CAN, 2000, Art.14). Por ello, la patente pretende proteger el uso de la información relativa a la invención por parte de terceros no autorizados.

Al ser el objeto de la protección el uso de la información, la patente se encuentra frente a las dificultades de protección propias que reporta un bien que comparte las características económicas de un bien público.

La información en sí misma no es susceptible de apropiación material. Por el contrario es de muy fácil reproducción y uso por los terceros, una vez ésta ha sido publicada o utilizada por primera vez. Ella se puede copiar y reproducir sin generar perjuicio a sí misma, es decir, la información no se disminuye ni se apoca con su repetido uso por parte de diversos sujetos. Señala Alberto Benegas Lynch que:

"un bien público es aquel que produce efectos sobre quienes no han participado en la transacción. Es decir, aquellos que producen efectos para terceros o externalidades que no son susceptibles de internalizarse. En otros 


\begin{abstract}
términos, aquellos bienes que se producen para todos o no se producen puesto que no se puede excluir a otros. Por ejemplo, un bien público sería un perfume agradable que usa una persona y que otros disfrutan, mientras que un bien privado sería el uso del teléfono que sólo beneficia al usuario. Asimismo, los bienes públicos tienen la característica de la no-rivalidad, lo cual significa que el bien no disminuye por el hecho de que lo consuma un número mayor de personas. En nuestro ejemplo, no se consume el perfume por el hecho de que un número mayor de personas aproveche el aroma. En consecuencia, los principios de no-exclusión y no-rivalidad caracterizan al bien público, lo cual, a su turno, significa que tienen lugar externalidades, es decir, como queda dicho, que gente se beneficia del bien sin haber contribuido a su financiación (free-riders) o también, en otros casos, gente que se perjudica (externalidades negativas o costos externos) situación ésta última en la que los free-riders son los emisores de externalidades." $(1997,3)$
\end{abstract}

En otras palabras cuando el inventor halla una cierta información innovadora, capaz de producir un producto o un proceso desconocido previamente, encuentra un bien que no es rival, que no excluye a los terceros y que puede ser utilizado por ellos, aún cuando no hayan participado en su hallazgo, sin afectar al bien mismo, es decir a la información. Por lo anterior, el perjuicio que sufre el inventor con el uso no autorizado de su invención no es en atención a la invención en sí misma, sino con la pérdida de oportunidad de no haberse lucrado con el uso de su descubrimiento. Así la patente se entiende como un monopolio legal temporal de explotación que excluye a los terceros no autorizados del uso de la información descubierta por el inventor.

De lo anterior nace uno de los interrogantes más importantes en torno a la teleología de la patente de invención: la patente de invención existe para excluir del uso de la información a los terceros no titulares del privilegio, o la patente de invención existe para excluir del uso gratuito a los terceros no titulares del privilegio.

La respuesta a dicha pregunta definirá el sentido legal de dicha institución jurídica, en la medida que si la finalidad de la misma es la exclusión a terceros del uso de la información, la patente implicaría la titularidad de la información en sí misma, pero si por el contrario implica la exclusión del uso gratuito a los terceros, la patente implica una apuesta por la difusión de la información mediante el uso de instrumentos contractuales adecuados para que el inventor reporte beneficio económico universalizando en la mayor medida y necesidad, la invención obtenida y se justificaría la intervención del Estado en la medida en que el titular privatice la información más allá de los límites razonables o justos.

\title{
La patente y sus finalidades en la doctrina
}

Al monitorear la doctrina se encuentran teorías que han circunscrito la teleología de la protección de la propiedad industrial al ámbito de salvaguardar a) la inversión y capital invertido, b) la protección del ingenio y trabajo humano, y c) la importancia de fomentar la cultura, la ciencia y la tecnología. 
En atención de ubicarse en una y otra, cada autor señala las características propias que deberían tener los regímenes de protección, es más fuerte en algunos la protección del capital y en los otros la promoción de acceso a la ciencia y a la tecnología. En atención a la protección del ingenio y trabajo humano otras doctrinas la complementan con otro tipo de estímulos como honores y bonificaciones del gobierno para el autor o inventor. También existe, sobre todo al tenor de la doctrina económica de la competencia y libre mercado, la postura de algunos doctrinantes que plantean la inconveniencia de las patentes, en atención a lo nocivo que resulta la intervención del mercado mediante monopolios legales.

En primer lugar la vertiente tradicional u ortodoxa, que resume muy bien el autor Agustín Ramella, en su libro Tratado de la Propiedad Industrial, señala estas ideas:

Así como "el trabajo es la fuente originaria y también el fundamento jurídico de la propiedad, es justo que el autor de inventos pueda invocar dicho principio para sujetar a su propio exclusivo dominio sus inventos y descubrimientos en el terreno de la industria”. (Ramella, 1913, 11)

En este sentido el autor se encuentra en una postura que profesa la protección de las invenciones tanto como producciones del capital, como producciones del esfuerzo inventivo humano, trabajo humano no sólo entendido como esfuerzo, sino también como medio de producción, es decir como capital.

Deberá protegerse el trabajo del inventor puesto que él:

“(...) a menudo, después de considerables indagaciones y consumo de tiempo y de gastos, logra crear nuevos y mejores medios de producción, bien debe merecer una compensación al par de quien ejerce otra profesión cualquiera o se consagra a otra forma de producción.” (Ramella, 1913, 11).

De otro lado el autor dejado a un lado este problema, aborda la legitimidad de dicha protección, pues reconoce que el conocimiento nunca se produce por sí solo requiriendo inversión de capital y esfuerzo, aunque se suela construir sobre los preconceptos y saberes de la humanidad que no pueden ser apropiables. No resultaría además adecuado dejar al azar, sin el estímulo de la protección, la labor inventiva y productiva del nuevo saber, pues se tornaría en un proceso muy lento en detrimento del beneficio social. (Ramella, 1913).

Como se advierte de lo anterior, el autor de todas formas señala el acceso a la cultura como parte de la protección de la propiedad industrial, pero no como causa, sino como consecuencia de la misma.

En razón con otro tipo de estímulos para el inventor como el honor y el reconocimiento social, Ramella señala que no son estímulos suficientes ya que el dinero es el primer y más fuerte estímulo de las personas, por lo que "si el inventor no pudiera esperar una ventaja económica de su propio descubrimiento, ninguno querría emplear sus esfuerzos y dinero en semejantes investigaciones en completo daño de la sociedad" (Ramella , 1913, 12). 
Tampoco considera viable que sea otro tipo de privilegio como, por ejemplo, dejar libres las invenciones a condición que los industriales pagaran una retribución a los inventores, ya "sea por la imposibilidad de su exacta comprobación, sea porque, abandonado el éxito del invento a la obra no siempre inteligente y leal de otros fabricantes, podría el invento exponerse a su descrédito y a concurrencia desleal." (Ramella, 1913, 11)

Finalmente, señala que de suprimirse la legislación sobre patentes, florecería la industria de secretos industriales, lo que sería más perjudicial para la sociedad, en razón de no poder ser conocidos los inventos de manera diáfana como ocurre con la petición de patente. (Ramella, 1913).

Por otro lado la doctrinante española Luisa Llobregat Hurtado, encarna una línea similar a la esbozada por Ramella, dándole más relevancia al tema cultural, pero sin perder de vista, como el centro, la protección de la inversión humana y monetaria. Así que la autora señala:
"En relación con la finalidad perseguida por los derechos de propiedad industrial y el derecho de autor, si bien no podemos negar que los primeros son instrumentos para que las empresas puedan operar en un mercado que protege la libre competencia, el derecho de autor tiene por el contrario como finalidad esencial la protección y el fomento de la cultura. Parece razonable sostener que en la actualidad ambas finalidades se encuentran en ambos derechos y ello es así porque la tradicional línea divisoria entre ellos se ha ido difumando. Por otro lado, la propia noción de cultura de una sociedad se ha ido ampliando, y en la actualidad parece oportuno aceptar que de la misma manera que existe una conexión del derecho autor con las actividades económicas, también existe una conexión entre los derechos de la propiedad industrial y el desarrollo cultural." (Llobregat, 2002, 30)

Así la finalidad de la protección de la propiedad industrial e inclusive de la propiedad intelectual de los derechos de autor es pecuniaria y de competencia empresarial, relacionándose también con la cultura ya que la tecnología permite su promoción y difusión. (Llobregat, 2002).

En la doctrina Colombiana, encontramos al profesor Ernesto Rengifo García, y su trabajo denominado "Propiedad Intelectual el moderno derecho de autor" (2003). El cual sitúa en una misma categoría jurídica "al inventor, al autor y al usuario de signos mercantiles" (Rengifo, 2002, 24) en atención a que los tres cumplen una función monopolística y concurrencial.

Otro sector de la doctrina ofrece a la protección de la propiedad industrial una función eminentemente cultural. Por ejemplo, el doctrinante venezolano Thaimy Márquez, en su artículo Aprovechamiento de la información tecnológica contenida en patentes para el desarrollo de la ciencia y las empresas, publicada en la Revista Venezolana de Economía y Ciencias Sociales. Vol. 11 No. 1. Año 2005. Señala que: 
"El Sistema de Patentes (SP) descansa sobre la base de su función social, esto es, este sistema debe contribuir a la promoción de la innovación tecnológica y a la transferencia y difusión de la tecnología en beneficio de los productores y los usuarios de conocimientos tecnológicos, para que favorezcan el bienestar social y económico. Para ello, cuando el Estado concede una patente (uso temporal exclusivo del objeto de una invención), obliga a su titular a efectuar una descripción clara y completa, a fin de divulgar la invención para su comprensión y para que personas capacitadas en la materia técnica correspondiente puedan ejecutarla. Se persigue que la invención pueda repetirse con la información que se aporta y, por ende, que pueda servir de base y sustento a otras innovaciones." (Márquez, 2005, 185).

De esta forma, para este autor la función relevante para la concesión de una patente, es el fomento a la cultura y a la ciencia. Continúa el análisis mediante el estudio de los presupuestos para la protección de la propiedad industrial. En particular, cuando aborda el estudio de uno de los requisitos para conseguir la patente de invención, como lo es la publicación en el registro de cada país, advierte que el fin de dicha protección es, a su vez, poner de presente a la sociedad, de manera rápida y expedita el conocimiento, para que este pueda ser utilizado de forma eficiente por las demás personas. En este sentido, las universidades deberían acceder de manera más sistemática a la información guardada por las oficinas encargadas de la propiedad industrial para que cumplieran la real función social que la ley les otorga. (Márquez, 2005)

Dichas posturas doctrinales necesariamente implican que la protección de la propiedad industrial mediante monopolios legales se hace con el fin de obtener información rápida y veraz para su uso inmediato con fines no comerciales. En este sentido resulta falso pensar que la información patentada no puede ser utilizada so pena de violar la patente por parte de terceros, sin autorización del titular, en ningún caso, pues los usos no comerciales no están prohibidos, ni allí es oponible el derecho de exclusividad (Decisión 486, 2000, Art. 65). En este sentido la patente no confiere la exclusividad de la información, sino la exclusividad comercial de la información, por el tiempo previsto.

\section{La patente y sus finalidades a la luz de los derechos humanos}

La normatividad relativa a los derechos humanos también trata el tema de la propiedad industrial y su protección elevándola a la categoría de derecho. Al hacerlo le imprime una carga axiológica importante pues empodera al inventor en relación con su invención.

Sin embargo no sólo empodera al inventor, sino que también devela en su principialística la fuerte apuesta por el acceso a la ciencia y a la tecnología de la 
humanidad. En otras palabras, se consagra como un derecho de naturaleza "dual"2 o mejor de doble vía Así la norma desde su génesis ius humana implica una colaboración armónica ${ }^{3}$ entre los sujetos, inventor y usuario de la invención.

La Declaración Universal de los Derechos humanos de la ONU, en su Art. 27 reza lo siguiente:

"ART. 27: 1. Toda persona tiene derecho a tomar parte libremente en la vida cultural de la comunidad, a gozar de las artes y a participar en el progreso científico y en los beneficios que de él resulten. 2. Toda persona tiene derecho a la protección de los intereses morales y materiales que le correspondan por razón de las producciones científicas, literarias o artísticas de que sea autora." (Declaración Universal de los Derechos Humanos, 1948)

Igualmente en la declaración americana de los derechos del hombre encontramos el Art. XIII que reza:

"Art. XIII: Toda persona tiene el derecho de participar en la vida cultural de la comunidad, gozar de las artes y disfrutar de los beneficios que resulten de los progresos intelectuales y especialmente de los científicos. Tiene así mismo derecho a la protección de los intereses morales y materiales que le correspondan por razón de los inventos, obras literarias, científicas o artísticas de que sea autor" (Declaración Americana de los Derechos y Deberes del Hombre, 1948)

De modo que en el mismo canon que está elevado como derecho humano el derecho al acceso a la ciencia y a la tecnología, también se encuentra elevado a derecho humano la protección de los intereses particulares derivados de la protección de la propiedad industrial. Es imposible entonces pensar ambos componentes como elementos aislados. Al contrario, son distintas ópticas de una misma realidad para el derecho, así, El acceso a la ciencia y a la tecnología es un derecho que necesita ser desarrollado mediante la capacidad inventiva de los hombres, por lo tanto es imprescindible protegerla y estimularla, en favor de la humanidad.

Desde esta perspectiva el ordenamiento jurídico implica una armonización entre a) el derecho al acceso a la ciencia y la tecnología de toda persona y b) el derecho a la protección patrimonial de las invenciones; entre a) el acceso a la ciencia y a la tecnología, y c) el derecho al lucro personal con las propias invenciones. De esta

2 Se caracteriza como "dual" en razón de su naturaleza de doble vía, es decir, que implica necesariamente un inventor de un adelanto científico y, por otro lado, un consumidor o destinatario del mismo, de modo que no puede entenderse el primero sin la existencia del segundo, ya que es un derecho que implica interacción y satisfacción mutua de necesidades.

3 Entiéndase colaboración armónica en el sentido de armonización concreta, es decir, que ha de procurarse que la tensión de derechos no implique menoscabo de ninguno de los dos extremos, sino materialización mutua, en la medida de las posibilidades. 
manera mientras el accionar de los particulares implique el desarrollo de ambas facetas, se logrará dicha finalidad legal, de lo contrario se deberá resolver la tensión, ya sea a favor del acceso a la ciencia y a la tecnología o a favor del derecho del inventor a ser protegido en su interés patrimonial, según el caso concreto.

\section{La patente y sus finalidades en el ordenamiento internacional}

No son abundantes las normas que nos remitan de forma directa a la teleología jurídica de la patente de invención, no obstante estas tampoco son inexistentes en el ordenamiento jurídico, de modo que se constituyen en otro insumo fundamental en orden a conseguir la tara iniciada.

El tratado de los Aspectos de la Propiedad Industrial relacionados con el Comercio, (ADPCIC), ANEXO 1C del acuerdo de Marrakech, fundante de la Organización Mundial del Comercio (OMC) y el tratado de Cooperación Internacional en Materia de Patentes (PCT), ofrecen algunos artículos que ofrecen luz:

El acuerdo de los ADPIC, en el artículo 7, refiere cuáles son los objetivos de la protección de la propiedad industrial, en atención al comercio:

"La protección y la observancia de los derechos de propiedad intelectual deberán contribuir a la promoción de la innovación tecnológica y a la transferencia y difusión de la tecnología, en beneficio recíproco de los productores y de los usuarios de conocimientos tecnológicos y de modo que favorezcan el bienestar social y económico y el equilibrio de derechos y obligaciones" (ADPIC, 1994, Art. 7)

En el mismo sentido, el artículo 8 del mismo tratado, refiere los principios de la protección, en los siguientes términos:

“1. Los Miembros, al formular o modificar sus leyes y reglamentos, podrán adoptar las medidas necesarias para proteger la salud pública y la nutrición de la población, o para promover el interés público en sectores de importancia vital para su desarrollo socioeconómico y tecnológico, siempre que esas medidas sean compatibles con lo dispuesto en el presente Acuerdo.

2. Podrá ser necesario aplicar medidas apropiadas, siempre que sean compatibles con lo dispuesto en el presente Acuerdo, para prevenir el abuso de los derechos de propiedad intelectual por sus titulares o el recurso a prácticas que limiten de manera injustificable el comercio o redunden en detrimento de la transferencia internacional de tecnología" (ADPIC, 1994, Art. 8)

Como se advierte, tanto en los objetivos como en los principios del tratado, la legislación internacional imprime un fuerte valor a aquella primera parte del derecho humano dual referido, es decir al acceso a la ciencia y a la tecnología como elemento fundamental de la protección. Como aspectos relevantes se consagran la salud pública, la nutrición de las personas, el desarrollo socioeconómico, proscribiendo el abuso de los derechos de propiedad industrial. 
De otro lado en el tratado PCT inicia con unos considerandos que declaran el sentido de la norma consagrada en el tratado así:

\begin{abstract}
"Deseando contribuir al progreso de la ciencia y la tecnología, Deseando perfeccionar la protección jurídica de las invenciones, Deseando simplificar y hacer más económica la obtención de protección para las invenciones, cuando se desee esta protección en varios países, Deseando facilitar y acelerar el acceso público a la información técnica contenida en los documentos que describen las nuevas invenciones, Deseando fomentar y acelerar el progreso económico de los países en desarrollo mediante la adopción de medidas destinadas a incrementar la eficacia de sus sistemas jurídicos de protección de las invenciones, tanto a nivel nacional como regional, proporcionándoles información fácilmente accesible sobre la disponibilidad de soluciones tecnológicas aplicables a sus necesidades específicas y facilitándoles el acceso al volumen en constante expansión de la tecnología moderna, Convencidos de que la cooperación entre las naciones facilitará en gran medida el logro de esos objetivos, (...)" (PCT, 1970, 6) (subrayado por fuera de texto).
\end{abstract}

Al leerse en los subrayados, se introducen nuevos elementos a la teleología de la institución como lo es la divulgación de la ciencia y la tecnología. Así dichos considerandos ofrecen un forma de equilibrio entre el acceso a la ciencia y a la tecnología como derecho humano de las colectividades, y el derecho individual de la protección de la propiedad industrial, el cual ya se había develado anteriormente.

Es relevante que hasta el momento no se ha encontrado una norma que expresamente señale que la protección del capital privado sea una motivación o causa de la protección de la propiedad industrial en un sentido principal, sino siempre subordinado a otro tipo de intereses.

\title{
Las patentes y sus finalidades en el ordenamiento comunitario
}

El ordenamiento comunitario no es indiferente a dicha tensión entre el acceso a la ciencia y la tecnología y el interés particular del inventor y también se encuentra cargado de un fuerte contenido axiológico que se desarrolla en el mismo sentido propuesto anteriormente: se protege el interés particular únicamente en la medida en que con esto resulte satisfecho el interés general del acceso a la ciencia y la tecnología.

Para encontrar dicha realidad legal podemos acudir en la Norma Andina en lo relativo a: a) los requisitos de la patentabilidad, b) deberes de la patente, y c) Licencia Obligatoria y excepciones al uso exclusivo de la patente.

\section{REQUISITOS DE PATENTABILIDAD}

En la decisión 486 la Norma Andina exige como requisitos para poder conceder una patente de invención, que el producto o proceso sea novedoso, tenga nivel 
inventivo y sea susceptible de aplicación industrial (Decisión 486, 2000, Art. 14). En otras palabras, si la solicitud de patente sobre el producto o el principio no cuenta con dichos requisitos, deberá ser rechazada la solicitud de patente por la oficina nacional encargada, que en este caso es la superintendencia de industria y comercio. Por ello, la intención del legislador, al consagrar dichos requisitos, es incentivar a que las personas logren productos o procesos nuevos, innovadores y susceptibles de aplicación industrial, y por lo tanto que sus investigaciones se enfilen a tal objetivo. De tal suerte que si alguien obtiene un producto útil, pero que no es nuevo y es carente de nivel inventivo, podrá utilizarlo, pero no podrá hacerlo de forma exclusiva, pues no se le conferirá la prerrogativa de la patente.

En palabras del Tribunal Andino de Justicia el producto o proceso para que sea patentable debe ofrecer a la ciencia y a la técnica verdaderos saltos cualitativos en la ciencia y en la técnica. (Tribunal Andino de Justicia Proceso 64 IP, 2010). Bajo esta perspectiva desaparece como una teleología del sistema de patentes la protección del capital invertido, al menos como finalidad del modelo, ya que si la protección del capital fuese la finalidad principal del sistema de patente, debería privilegiarse la protección de los productos o procesos encontrados en la labor investigativa en relación con la cantidad de capital invertido y no en atención a su nivel inventivo. En otras palabras, si algún inventor, de modo afortunado encontrase un nuevo producto o un proceso innovador, nuevo y susceptible de aplicación industrial de forma gratuita o muy económica, no debería concederse patente de invención a este, pues no se cumpliría con el requisito de la inversión de capital, y en tal sentido debería recibir una protección proporcional al mismo, es decir, mínima o nula. Así mismo, si la causa de la protección de la propiedad industrial fuese el capital, deberían protegerse las fuertes inversiones en investigación, aunque estas no obtuvieran un producto nuevo, innovador y útil, pues no sería justa entonces la desprotección del capital inyectado a la ciencia y la tecnología.

No obstante, no existe siquiera una protección más fuerte o más débil de la patente en atención al capital invertido o al esfuerzo desplegado para el desarrollo de la invención. En este sentido en el supuesto que una persona efectúe innumerables inversiones en investigación y logre resultados útiles, pero que no consigan a cabalidad los requisitos exigidos por la norma, podrá explotar su hallazgo, pero nunca de forma exclusiva. En cambio, si por un golpe de suerte se halla un producto o proceso que cumpla tales características, éste sí logrará la protección exclusiva deseada, de modo que la normatividad arroja claramente que protege no las inversiones sino los adelantos, respondiendo al paradigma ya reseñado ut supra que es mejor incentivar la producción de ideas inexistentes mediante un monopolio de explotación a su inventor, con tal que esta se produzca con altura inventiva, que no incentivar de forma alguna la producción de tal adelanto. 


\section{Las características de patentabilidad según el Tribunal Andino de Justicia}

Las características de novedad y nivel inventivo han sido estudiadas ampliamente por El tribunal Andino de Justicia. La Norma Andina define la característica de novedad para la concesión de una patente el artículo 16 de la decisión 486 de la CAN, señala que algo será nuevo cuando no exista con anterioridad en el estado de la técnica. El Tribunal Andino de Naciones ha explicado tal definición y señala que la verificación de la novedad se hará al comprar el producto o proceso solicitado para protección con cada uno de los productos o procesos existentes en el estado de la técnica de forma aislada. Igualmente ha complementado diciendo que la novedad de lo solicitado debe ser mundial, para considerarse como tal (Tribunal Andino de Naciones, Interpretación prejudicial 88 IP 2005).

Por otro lado, en lo relativo al nivel inventivo la norma andina señala que un producto o proceso posee nivel inventivo cuando no se derive ni evidente ni obviamente del Estado de la Técnica (Decisión 486 CAN, 2000, Art. 18). En otras palabras, si estudiar la novedad implica comparar lo que se solicita patentar con cada uno de los componentes existentes en el estado de la técnica de forma aislada, el estudio del nivel inventivo implica que se efectúe dicho cotejo pero con elementos conformantes del estado de la técnica en forma conjunta, con el ánimo de encontrar si era fácilmente deducible de aquél. Para lograr este requisito no es imprescindible que la invención no se base en el estado de la técnica, pues esto es imposible, sino hace falta que lo pedido no sea una simple combinación que pueda ser derivada del mismo, sino que su descubrimiento haya requerido algún trabajo y dificultad por parte del inventor.

Se puede entrever en la jurisprudencia del tribunal reitera la teleología hasta ahora señalada. Se reitera que el sistema no pretende proteger las inversiones que los empresarios efectúen en sus invenciones, pues no se exige como requisito para patentar un invento que se presente la cantidad invertida, ni es siquiera requisito para la patentabilidad, haber efectuado una inversión, dicha realidad será una consecuencia, pero no la causa de la patente. Por otro lado, en cambio, sí es requisito que el producto o proceso que se va a patentar sea nuevo y contenga nivel y altura inventiva. La patente se confiere como recompensa a haber conseguido el inventor un auténtico salto cualitativo en la ciencia o en la técnica correspondiente.

\section{Las obligaciones y prohibiciones del titular de la patente}

La norma andina no solamente pretende incentivar los avances sino, además, que dicho progreso se irradie de forma efectiva la vida social de las personas. El ordenamiento jurídico señala como una obligación del titular de la patente explotar la invención en forma suficiente de acuerdo a las necesidades del mercado (Art. 59 Decisión 486, CAN). Al ser una obligación que el titular de la patente explote 
su invención, sería ilegítimo a la luz del sistema de patentes que la exclusividad concedida tenga por fin únicamente excluir a los terceros sin la realización de actos de explotación.

De otro lado, la norma andina igualmente prohíbe patentar lo que ya se encuentra en el estado de la técnica, este último es todo aquello que ha entrado al dominio público. Señala el artículo 16 de la norma andina lo siguiente:

\footnotetext{
"El estado de la técnica comprenderá todo lo que haya sido accesible al público por una descripción escrita u oral, utilización, comercialización o cualquier otro medio antes de la fecha de presentación de la solicitud de patente o, en su caso, de la prioridad reconocida." (Art. 16, Decisión 486 CAN).
}

Dicha definición ha sido ampliada también por la jurisprudencia del Tribunal Andino de Justicia, pues "todo lo que haya sido accesible" se refiere en cualquier parte del mundo, y no únicamente a la circunscripción territorial de la oficina encargada. (Tribunal Andino de Justicia, Interpretación prejudicial 88 IP 2005). Puede inferirse que el sistema no quiere quitarle a la sociedad lo que ya se le ha dado como conocimiento para volverlo exclusivo.

Finalmente, el hecho de solicitar una patente en una oficina encargada de propiedad industrial, a su vez, incorpora la invención en el estado de la técnica para todo el mundo. Por esta razón la norma de propiedad industrial prevé la figura de la reivindicación de prioridad, que consiste en un tiempo de gracia para que el inventor de un producto o proceso patentado pueda pedir en una parte del mundo diferente a donde ya solicitó la patente, que se le proteja el mismo producto, sin tener en cuenta que este ya ingresó al estado de la técnica. Si el inventor deja transcurrir dicho término, la invención efectuada habrá ingresado al estado de la técnica y, por lo tanto, ni él mismo podrá pedir patente sobre su invención en otro lugar del mundo diferente al que la consiguió.

Otra limitación en la oponibilidad del derecho se encuentra en el artículo 53 de la decisión 486 de 2000 de la Comisión del Acuerdo de Cartagena. Esta consiste en la imposibilidad de oponer el derecho de patente ante los actos realizados en el ámbito privado y con fines no comerciales, actos realizados exclusivamente con fines de experimentación, actos realizados exclusivamente con fines de enseñanza o de investigación científica o académica, entre otros. De modo que se explicita como la institución en cuestión bajo ninguna circunstancia prevé la monopolización de conocimiento, sino por el contrario su difusión.

Sin ser los anteriores un estudio exhaustivo de los requisitos de patentabilidad, las excepciones a la patentabilidad y los deberes del titular de la patente, sí señalan claramente como la titularidad que la figura concede no es en relación con la información, de modo que pudiera ésta, en sí misma, sacarse del uso público, sino permite la explotación exclusiva, e inclusive, como se verá, incentiva el uso de instrumentos contractuales para un uso masivo comercial de la información protegida. 


\title{
La licencia obligatoria
}

La licencia obligatoria es una figura especial de excepción a la protección exclusiva de la propiedad industrial. Ella está consignada tanto en la normatividad andina (Decisión 486 CAN, 2000, Artículo 65), en el Tratado de París que funda la Organización Mundial de la Propiedad Industrial (OMPI) (Tratado de París, OMPI, 1883, Artículo 5) y en el tratado de los ADPIC (ADPIC, 1994, Artículo 31). Mediante ella el ejecutivo puede permitir que un tercero, no titular de la patente, explote una invención protegida en razón a varias razones: a) interés público, b) falta de explotación de la patente por parte del titular, c) imposibilidad de acuerdo contractual para explotar una segunda invención que requiera de la primera, y d) corregir prácticas anticompetitivas de abuso de la explotación exclusiva de la patente de invención. En todos los casos, salvo en el c), el poder ejecutivo deberá determinar el monto de un derecho a favor del titular de la patente en compensación al uso no exclusivo.

Esta figura termina de fraguar la teleología de la patente de invención, pues delimita definitivamente como ésta no implica un monopolio de explotación de la información, sino una prohibición de explotación gratuita por parte de terceros no autorizados, ya que la figura permite el uso de la información, sin el consentimiento del titular de la patente, reconociendo por parte del Estado una retribución económica, salvo en el evento de corregir prácticas anticompetitivas.

\section{La patente y el derecho de consumo, el aprovisionamiento}

La patente de invención, como se esbozó al principio, no tiene sentido por fuera de la órbita del consumidor. Debido a ello es necesario determinar en qué punto se entrelazan ambos cuerpos normativos.

El derecho de Consumo es de especial relevancia para nuestro ordenamiento jurídico. Nace desde la Constitución misma consagrado como un derecho en el título segundo, capítulo tercero denominado "De los Derechos Colectivos y del Ambiente".

\begin{abstract}
"La ley regulará el control de calidad de bienes y servicios ofrecidos y prestados a la comunidad, así como la información que debe suministrarse al público en su comercialización. Serán responsables, de acuerdo con la ley, quienes en la producción y en la comercialización de bienes y servicios, atenten contra la salud, la seguridad y el adecuado aprovisionamiento a consumidores y usuarios. El Estado garantizará la participación de las organizaciones de consumidores y usuarios en el estudio de las disposiciones que les conciernen. Para gozar de este derecho las organizaciones deben ser representativas y observar procedimientos democráticos internos." (Constitución Política de Colombia, 1991, Art. 78)
\end{abstract}

De su tenor literal, pueden extraerse al menos cuatro núcleos esenciales: 

a. La calidad de los bienes y servicios
b. La información suministrada en la comercialización
c. La responsabilidad de los productores por los perjuicios
d. La responsabilidad de los productores por el correcto aprovisionamiento.

\title{
La Corte Constitucional en sentencia C 1140 de 2000 señaló lo siguiente:
}

"Los derechos del consumidor, no se agotan en la legítima pretensión a obtener en el mercado, de los productores y distribuidores, bienes y servicios que reúnan unos requisitos mínimos de calidad y de aptitud para satisfacer sus necesidades, la cual hace parte del contenido esencial del derecho del consumidor. El derecho del consumidor, cabe advertir, tiene carácter poliédrico. $\mathrm{Su}$ objeto, en efecto, incorpora pretensiones, intereses y situaciones de orden sustancial (calidad de bienes y servicios; información); de orden procesal (exigibilidad judicial de garantías; indemnización de perjuicios por productos defectuosos; acciones de clase y demás); de orden participativo (frente a la administración pública y a los órganos reguladores)." (Corte Constitucional, Sentencia C 1140 del 2000)

Como puede advertirse se tocan de lleno los tres primeros principios extraídos del Artículo 78 de la Constitución Política (calidad de los bienes, información y responsabilidad por daños) pero no se refiere la Corte Constitucional al adecuado aprovisionamiento, al menos en dicha sentencia, que es una de las más relevantes en la temática. En el estatuto del consumidor ocurre la misma situación, dentro de los principios rectores no se toca el tema del aprovisionamiento como parte fundante del derecho del consumidor:

\begin{abstract}
"Principios generales. Esta ley tiene como objetivos proteger, promover y garantizar la efectividad y el libre ejercicio de los derechos de los consumidores, así como amparar el respeto a su dignidad y a sus intereses económicos, en especial, lo referente a: 1 . La protección de los consumidores frente a los riesgos para su salud y seguridad. 2. El acceso de los consumidores a una información adecuada, de acuerdo con los términos de esta ley, que les permita hacer elecciones bien fundadas. 3. La educación del consumidor. 4. La libertad de constituir organizaciones de consumidores y la oportunidad para esas organizaciones de hacer oír sus opiniones en los procesos de adopción de decisiones que las afecten. 5. La protección especial a los niños, niñas y adolescentes, en su calidad de consumidores, de acuerdo con lo establecido en el Código de la Infancia y la Adolescencia.” (Ley 1480, 2011, Artículo 1)
\end{abstract}

De modo que en la doctrina Constitucional relevante y en los principios que inspiran la legislación del consumo no se trata el tema de aprovisionamiento de bienes y servicios como contenido importante del derecho de los consumidores.

Desde esta perspectiva el derecho de consumo y el derecho de patentes se entrelazan con la teleología de la patente a partir del derecho al correcto 
aprovisionamiento de bienes y servicios. Ya se ha corroborado como en los diversos ordenamientos jurídicos no se tolera el abuso de la exclusividad de la patente para excluir información innovadora del beneficio común de la humanidad, atentando contra el correcto aprovisionamiento como derecho de los consumidores, en concordancia con el derecho al acceso a la ciencia y la tecnología consagrado tanto en la Declaración Universal de Derechos del Hombre y la Declaración Americana de los Derechos del Hombre y del Ciudadano, como ya se ha referido. No obstante esta perspectiva es inexplorada en forma suficiente en la dogmática jurídica, tanto del consumo como de la patente de invención.

\section{EI TLC un posible cambio de paradigma}

EL TLC entre la República de Colombia y Estados Unidos de América trata de forma directa el tema de la propiedad industrial, y de la patente de invención. Dicho tratado, en líneas generales se circunscribe hasta lo acá precisado a la teleología de la patente. Por ejemplo, en el capítulo 16,9 relativo a patentes, como excepciones a la patentabilidad se consagra:

“3. Cada Parte podrá prever excepciones limitadas de los derechos exclusivos conferidos por una patente, a condición de que tales excepciones no atenten de manera injustificable con la explotación normal de la patente, ni causen un perjuicio injustificado a los legítimos intereses del titular de la patente, teniendo en cuenta los intereses legítimos de terceros." (TLC EUA-COL, $2011,16,9,3)$

No obstante, se encuentra una contradicción fuerte, en atención a la teleología acá referida en el punto en los 6.a y 10. Del capítulo referido:

“6. a. Cada Parte dispondrá los medios para y deberá, a solicitud del titular de la patente, compensar por retrasos irrazonables en la expedición de la patente, restaurando el término de la patente o los derechos de patente. Cualquier restauración deberá conferir todos los derechos exclusivos de una patente sujetos a las mismas limitaciones y excepciones aplicables a la patente original. A efectos de este subpárrafo, un retraso irrazonable deberá incluir al menos un retraso en la expedición de la patente de más de cinco años desde la fecha de presentación de la solicitud en el territorio de la Parte, o tres años contados a partir de la fecha en que se haya hecho la solicitud del examen de la patente, cualquiera que sea posterior, siempre que los períodos atribuibles a acciones del solicitante de la patente no se incluyan en la determinación de dichos retrasos. (...). "10. Con el fin de asegurar que la invención reclamada está suficientemente descrita, cada Parte dispondrá que la invención reclamada se considere suficientemente respaldada por su divulgación, cuando esa divulgación le indique razonablemente a una persona diestra en el arte que el solicitante estuvo en posesión de la invención reclamada, en la fecha de su presentación." 
Como puede advertirse, en el numeral 10 la divulgación de la información, propia de la patente de invención, no se refiere al hecho mismo de entregarla en forma suficiente y completa a la oficina encargada sino al hecho que el inventor posea la invención reclamada al momento que solicita la protección. Pareciera que esta norma incentivaría que aquella persona que desee conocer la patente, ya sea para explotarla con o sin fines comerciales, tanto como durante y después de la vigencia de la patente, a acudir al inventor, ya que la información entregada no sería tan relevante y, por lo tanto, no se requiere allí tanta completud. De esta forma se inclinaría más la balanza hacia la privatización no del derecho de explotación económica de la información, sino de la información en sí misma.

A pesar de la contravía clara que tiene esta norma frente a la teleología referida, no puede olvidarse que esta debe interpretarse mejor a la luz de los derechos humanos y del derecho al correcto aprovisionamiento de los consumidores, de modo que en la medida que la aplicación de esta norma genere perjuicios a la humanidad, en la no divulgación total de la información de la patente, deberá entenderse como violatoria de un ordenamiento superior que debe respetar.

De otro lado, en el TLC se encuentra, por ejemplo, en forma repetitiva el siguiente aparte:

\footnotetext{
"Ninguna Parte podrá bajo este párrafo disponer el pago de indemnizaciones contra una biblioteca, o un archivo, institución educativa u organismo público de radiodifusión sin fines de lucro, que sostenga la carga de la prueba de demostrar que no conocía o no tenía razones para creer que sus actos constituían una actividad prohibida."
}

De modo que pese a la contradicción encontrada, en líneas generales, el TLC respeta el espíritu de la patente de invención, como bien particular ordenado al bienestar comunitario de la humanidad.

\section{CONCLUSIONES}

A partir de los cuatro elementos señalados al principio como pilares del derecho de propiedad industrial, pudo hacerse un estudio sistemático de la misma desde la realidad fáctica de la patente de invención, pasando por la normatividad de derechos humanos, la específica del derecho mercantil y comunitario, la doctrina y desembocar en el derecho de consumo.

Estos cuatro pilares eran: a) que la normatividad de patentes se encuentra dispersa en diversas clases de fuentes heterogéneas a lo largo y ancho del ordenamiento jurídico, que b) que el legislador de la Institución de la Patente de Invención es, en la mayoría de los casos, el legislador internacional, en escenarios variados, que c) Los acuerdos políticos entre Estados, de acuerdo a las conveniencias de los Países, van fraguando el contenido de la protección de la propiedad industrial-patente, y que d) 
en la legislación de la Patente de Invención, entran en juego diversidad de intereses como el del empresario, el del consumidor y el de la humanidad en general, por desarrollarse en el marco de la innovación y, por lo tanto, del progreso de los pueblos. A partir de ellos al responder las preguntas ¿Cuál es la teleología de la patente de invención? Y ¿De qué forma deben resolverse los posibles conflictos de intereses entre los actores participantes en la innovación y el consumo de bienes innovadores? Se puede concluir que la patente de invención existe para excluir del uso gratuito de la información a los terceros no titulares del privilegio, pero bajo ninguna circunstancia para hacer exclusivo el conocimiento. Al respecto la sociedad está en mora de afrontar los registros de patentes como una gran enciclopedia universal de la ciencia, que puede ser consultada y reproducida con fines no comerciales, y explotada comercialmente mediante figuras contractuales que beneficien tanto al titular de la patente como a los interesados en ejercer la explotación comercial de las mismas.

Si bien es cierto la doctrina gira en torno a la protección de diversos valores mediante la propiedad industrial-patente, como son a) el capital invertido, b) el trabajo y c) el acceso a la ciencia y a la tecnología de los pueblos, las interpretaciones más modernas que estudian el tema a la luz de la principialística, inclinan la balanza hacia la protección del tercero de ellos como finalidad principal de la institución. Dicha caracterización se desprende a partir de la órbita de los derechos humanos, donde se encuentra una axiologización de la institución de la patente, que consiste en la justificación de la protección del capital privado invertido únicamente en la medida en que redunde en el beneficio del acceso a la ciencia y a la tecnología y el beneficio de los pueblos, evitando conductas abusivas o que generen perjuicio al valor del progreso de los pueblos. Esta carga principialística se encuentra armónicamente desarrollada en todas las instituciones particulares de la normatividad de propiedad industrial propiamente dicha, en acápites como los deberes del titular de la patente, como a) la explotación suficiente en términos de mercado, b) la imposibilidad de oponer el derecho a los terceros cuando ellos realicen actos no comerciales, c) la necesidad de publicación de la invención para que pueda ser consultada universalmente, d) la introducción de la patente al estado de la técnica, e) la pérdida del derecho a patentar en otras latitudes, si se deja fenecer el término de la prioridad, f) los requisitos de la patentabilidad ligados únicamente a la novedad, innovación y susceptibilidad de explotación comercial y no al monto invertido en el proceso de búsqueda de la patente, g) la licencia obligatoria y las flexibilidades especiales que aparecen cuando se acerca la patente a campos mayormente sensibles como la salud.

Dicha finalidad y axiologización también se encuentra consagrada expresamente en diversas codificaciones internacionales que aclaran de entrada la finalidad del derecho a patentar ligado al desarrollo de los pueblos y el acceso a la ciencia y a la tecnología, antes que la protección del capital privado.

Finalmente, hace falta un desarrollo doctrinal más fuerte de dicha ponderación de factores a la luz del derecho de consumo, el derecho de los consumidores al 
aprovisionamiento de bienes y servicios es el engranaje que entronca la legislación de propiedad industrial-patentes y sus limitaciones señaladas, con el derecho de consumo y la protección del acceso a la ciencia y a la tecnología.

\section{REFERENCIAS}

Aspectos de los Derechos de Propiedad Intelectual relacionados con el Comercio, (ADPIC), ANEXO 1C del Acuerdo de Marrakech por el que se establece la Organización Mundial del Comercio, Marrakech, Marruecos, 15 de abril de 1994, Art 7, 8, 31

Alberto, L. (1997). Bienes públicos, externalidades y los free-riders: el argumento reconsiderado, disponible en el sitio Web del grupo de investigación eumednet (SEJ-309) de la Universidad de Málaga, recuperado el 5 de Julio de 2011, http:// www.eumed.net/cursecon/textos/Lynch-bienes_publicos.htm

Constitución Política de Colombia, segunda edición corregida de la Constitución Política de Colombia, publicada en la Gaceta Constitucional No. 116 de 20 de julio de 1991, Art. 61, 78

Declaración Americana de los Derechos y Deberes del Hombre, Aprobada en la Novena Conferencia Internacional Americana, Bogotá, Colombia, 1948

Declaración Universal de los Derechos Humanos, 1948, artículo 27, disponible en http://www.un.org/es/documents/udhr/

Decisión 486 de la Comisión de la Comunidad Andina de Naciones, que decide Sustituir la Decisión 344 por la siguiente Decisión: REGIMEN COMUN SOBRE PROPIEDAD INDUSTRIAL, Lima, Perú 14 de Septiembre de 2000, disponible en http://www.comunidadandina.org/normativa/dec/D486.htm, recuperada el 8 de noviembre de 2011, Art. 14, 16, 18, 59, 65

Decreto 410 del Marzo 27 de 1971, Por el cual se expide el Código de Comercio, Art. 516.

Ley 457 de agosto 4 de 1998. Diario Oficial No. 43.360, de 11 de agosto de 1998. Disponible en http://www.secretariasenado.gov.co/senado/basedoc/ley/1998/ ley_0457_1998.html recuperado el 1 de noviembre de 2011.

Ley 57 de 1887, por la cual entra en vigencia el Código Civil de la Nación, sancionado el 26 de mayo de 1873, Art. 671.

Ley 1490 del 12 de Octubre de 2011, por medio de la cual se expide el Estatuto del Consumidor y se dictan otras disposiciones. D.O. 48.220, octubre 12 de 2011. Art. 1.

Llobregat, M. L. (2002). Temas de propiedad industrial, segunda edición, Madrid, Editorial La Ley, 30.

Márquez, Thaimy, (2005) Aprovechamiento de la información tecnológica contenida en patentes para el desarrollo de la ciencia y las empresas, publicada 
en la Revista Venezolana de Economía y Ciencias Sociales. Vol 11. No. 1. Año 2005, 185, disponible en http://site.ebrary.com/lib/bibliotecaustasp/ Doc?id=10212398\&ppg=2 recuperado el 4 de agosto de 2011.

PCT: Tratado de cooperación internacional en materia de patentes, 1978, elaborado en Washington el 19 de junio de 1970, enmendado el 28 de septiembre de 1979, modificado el 3 de febrero de 1984 y el 3 de octubre de 2001, OMPI, disponible en http://www.wipo.int/pct/es/texts/pdf/pct.pdf recuperado el 01 de agosto de 2011, Art. 6

Ramella, A. (1913). Tratado de la propiedad industrial, tomo primero, inventos industriales, Madrid, Hijos de Reus editores, 11 y 12.

Rengifo, E. (2003). Propiedad Intelectual el moderno derecho de autor, segunda edición, segunda reimpresión, Universidad Externado de Colombia, p. 24

Sentencia C 1141 del 2000, Referencia: expediente D-2830, Demanda de inconstitucionalidad contra los artículos 11 y 29 (parciales) del Decreto 3466 de 1982, MP. Dr. Eduardo Cifuentes Muñoz. Santafé de Bogotá, D.C., agosto treinta (30) de dos mil (2000)

Tratado de Libre Comercio entre Los Estados Unidos de América y la República de Colombia, Disponible en http:/www.tlc.gov.co/publicaciones.php?id=727 recuperado el 8 de noviembre de 2011, capítulo 16, Derechos de propiedad intelectual, Art. 9, numeral 3, numeral 6, numeral 10.

Tribunal Andino de Justicia, proceso 64-IP-2010, disponible en, http://www. lexbasecolombia.info/interpretacionespreja/064-ip-2010.htm, recuperado el 15 de febrero de 2011.

Tribunal Andino de Justicia, proceso 88 IP 2005, disponible en intranet. comunidadandina.org/Documentos/Procesos/88-ip-2005.doc recuperado el 8 de noviembre de 2011.

Tribunal Andino de Justicia, proceso 118 IP 2005, disponible en intranet. comunidadandina.org/Documentos/Procesos/118-IP-2005.doc recuperado el 8 de noviembre de 2011. 


\section{NORMAS DE PUBLICACIÓN}

La revista IUSTITIA de la Facultad de Derecho Universidad Santo Tomás (Seccional Bucaramanga), atendiendo al Departamento Administrativo de Ciencia, Tecnología e Innovación COLCIENCIAS y el Servicio de Indexación, expone las normas de publicación necesarias para la presentación de contribuciones:

Para la aceptación de los artículos por parte del Comité Editorial, se exigirá, que los artículos sean inéditos y originales (sin publicación parcial o total).

El artículo debe estar acompañado del Currículum Vitae completo del autor: nombre completo del autor, fecha completa de nacimiento, nacionalidad, nivel de escolaridad, nombre de la institución, centro de investigación, o institución a la cual pertenece, cargo que desempeña. Las publicaciones de artículos, capítulos de libros y libros deben presentarse (en el currículum) con toda la información correspondiente: Titulo, nombre de la revista o compilación, ISSN o ISBN, número de páginas total del texto completo, número de páginas del artículo o capítulo, año de publicación, editorial y país.

El texto debe presentarse en medio magnético, en formato Word, Normas APA, cuartillas 25 - 30, espacio medio, en letra Times New Roman 12, debe tener un resumen no superior a 10 renglones, abstract, palabras clave, key words. En relación con los anexos deben adjuntarse la lista de gráficas y cuadros, con su correspondiente numeración y página. Las tablas y figuras deben presentarse en formato original para poder hacer los ajustes necesarios de edición.

Los artículos recibidos serán remitidos a pares evaluadores, a quienes se les solicitara tener en cuenta en la evaluación, la calidad y el rigor académico del texto, como también la exigencia de las normas correspondientes a los trabajos académicos de publicación.

Recepción de artículos: Revista IUSTITIA: RevistaIUSTITIA@ustabuca.edu.co; coordinvder-ustabuca@hotmail.com

CP- Dirección para correspondencia (Sede Bucaramanga): Cra 18 No. 9 - 27. Bucaramanga - Santander - Colombia. PBX: 6800801 Ext. 2506.

La convocatoria (2013) para recibir artículos será entre Febrero 1 - Agosto 31. El idioma de publicación es el español, se aceptan artículos en inglés, francés y portugués, italiano. El Comité Editorial enviará comunicación sobre la aprobación o no de artículo, en un término no mayor a cuatro (4) meses.

Actualmente se tramitan procesos de registro ante la comunidad especializada. 
Esta obra se terminó de imprimir en el mes de diciembre de 2012 en la Universidad Santo Tomás, Bucaramanga - Colombia 